\title{
Accuracy in Social Perception: Contributions of Facial and Vocal Information
}

\author{
Diane S. Berry \\ Southern Methodist University
}

\begin{abstract}
The validity of social perceptions was assessed on the basis of facial or vocal information. Specifically, impressions of stimulus persons' power and warmth were obtained on the basis of either a facial photograph or a voice recording. These were compared with the stimulus persons' self-reports along the same dimensions. Face- and voice-based impressions did predict self-view. The specific facial and vocal characteristics that mediated these links were also considered. Potential mechanisms that may yield the match between self-perceptions and impressions based on nonverbal cues are discussed.
\end{abstract}

As people navigate their way through their social environment, a wealth of information is continually made available to them. During the past two decades, research in the area of person perception has mainly been focused on describing the kinds of errors that people are inclined to make when processing social information, as well as elucidating the causal mechanisms that yield those biases. In the rush to identify the conditions under which people may be wrong, however, psychologists seem to have forgotten that social perceivers also do, at least on occasion, manage to get things right. In fact, some researchers have suggested that when allowed to function in an environment more naturalistic than that characteristic of the typical person perception experiment, social perceivers are much more competent than the literature would lead one to expect (e.g., Berry, 1990a; Funder, 1987; McArthur \& Baron, 1983).

Within some domains of social perception, there has recently been a refreshing shift toward investigating the extent to which social perceivers are accurate in their judgments. One line of this work focuses on people's ability to detect the dispositional properties of others in lieu of extensive behavioral information. For example, Kenny and his associates (Albright, Kenny, \& Malloy, 1988; Kenny, Horner, Kashy, \& Chu, 1990) asked previously unacquainted college students to make "in person" ratings of one another's personality traits. Participants were found to demonstrate substantial agreement in their judgments of a particular target person's traits. Moreover, the impressions formed in these first encounters predicted self-ratings along a variety of dimensions. Using a similar methodology, Watson (1989) also found associations between self- and stranger ratings. Funder and Colvin (1988) reported greater than chance

Portions of these data were presented at the Nags Head Conference on Interaction Process and Analysis, Nags Head, North Carolina, June 1989. I am grateful to Julia Finch, Katie Hallett, and Paige Schaffer for their assistance in collecting the data reported here and to David Funder and the reviewers for their helpful comments on a draft of this article.

Correspondence concerning this article should be addressed to Diane S. Berry, Department of Psychology, Southern Methodist University, Dallas, Texas 75275 . agreement between individuals' self-ratings and judgments provided by strangers who viewed a 5 -min videotape of them participating in an interaction. Riggio, Lippa, \& Salinas (1990) similarly found that perceivers could detect extraversion and masculinity-femininity on the basis of watching videotapes of target persons delivering persuasive speeches.

These studies together suggest that social perceivers can indeed detect some dispositional properties of other people on the basis of relatively little information. What stimulus qualities make this knowledge available to perceivers? Nonverbal expressive behaviors, such as gestures, body movements, and eye contact, constitute one set of cues that plays an important role in this process. There is evidence that such qualities covary with and reveal certain dispositional properties, especially in individuals who are not likely to engage in impression management (see Lippa, 1983, for a review). Moreover, such cues may have been available in the "in person" rating studies described earlier and may account for their results.

Other research, however, indicates that perceivers can detect dispositional properties of others, even when expressive cues are not available. In a recent study, Berry (1990b) found evidence that perceivers can glean such information from the static appearance cues available in a photograph. Specifically, students participating in a psychology course provided personality judgments of one another during the 1st, 5th, and 9th weeks of the semester. Substantial agreement among raters was revealed at each time. A separate group of unacquainted raters also provided judgments of neutral expression facial photographs of the participants. These judgments were found to be significant predictors of personality impressions reported by classmates at each point in the semester. For example, people who were judged to be high in warmth on the basis of a facial photograph were also thought to be warm by classmates who had been acquainted with them for up to 9 weeks. These data suggest that aspects of static facial appearance may underlie the stranger-self agreement observed in the in-person rating studies described previously.

Another source that may be diagnostic of personality is vocal quality. Research has revealed that particular vocal parameters, like facial characteristics, are reliably associated with certain 
personality attributions (e.g., Scherer, 1972) and that perceivers do exhibit agreement in their judgments of strangers on the basis of vocal as well as facial qualities (e.g., Berry, 1990c; Scherer, 1972; Siegman, 1987). Finally, there is some evidence that particular acoustic characteristics may covary with particular dispositional qualities (e.g., Scherer, 1978). Together, these data lead to the intriguing idea that these sources may provide perceivers with some accurate information about inner disposition. Although such a "kernel of truth" hypothesis has occasionally been posited as one explanation of the reliable impressions that people form on the basis of facial or vocal information (e.g., McArthur, 1982; Siegman, 1987), such impressions have been more commonly regarded as evidence of stereotyping. Given the data described above, however, the question of whether relatively stable facial and vocal characteristics can provide a basis for accuracy in first impressions warrants attention. This possibility is examined in this study.

Personality judgments of stimulus persons that were based on either their facial photographs or recordings of their voices were compared with their self-ratings and scores on personality tests. The relative contribution of facial and vocal impressions as predictors of self-ratings was also considered. Finally, the question of whether the specific qualities of facial babyishness, facial attractiveness, or vocal babyishness might account for any links observed between face- or voice-based impressions and self-judgments of personality was assessed.

\section{Method}

\section{Stimulus Persons}

Eighty-six undergraduates ( 43 men and 43 women) served as stimulus persons in the study. Most received course credit for their participation.

\section{Stimulus Materials}

Stimulus persons were contacted and asked whether they would be willing to be photographed and to provide recordings of their voices for an ongoing research program on social perception. A release form provided permission for the use of the photographs and recordings in future research. Before the individuals were photographed, they were asked to remove their glasses and visible jewelry, and a dark cloth was wrapped around their shoulders to conceal their clothing. In accord with standard procedure in studies of impressions of faces, the subjects were instructed to maintain a neutral expression. Color slides of the photographs were prepared.

The stimulus persons' voices were recorded for approximately $15 \mathrm{~s}$ while they recited the alphabet. They were asked to speak in a neutral, normal tone of voice. This sampling procedure was selected because it retains information about vocal quality but keeps content neutral and equated (Montepare \& Zebrowitz-McArthur, 1987). Moreover, it eliminates many cues other than vocal quality that are available in conversational samples (e.g., interruptions and qualifiers).

\section{Perceptions of Stimulus Persons}

Dependent measure: Social perception. The stimulus persons' faces and voices were rated on 9-point bipolar scales that reflected power and warmth. These were selected because previous research has repeatedly documented that vocal and facial qualities influence impressions along these dimensions (e.g., Berry, in press; Berry, 1990c; Montepare \& Zebrowitz-McArthur, 1987). The specific scales used included weakstrong, cold-warm, shrewd-naive, assertive-not assertive, honest-dishonest, cruel-kind, vulnerable-invulnerable, submissive-dominant, and deceitful-straightforward.

Dependent measures: Facial and vocal qualities. If matches between face- and voice-based impressions and self-view were revealed, a second goal of the study was to try to identify the specific aspects of facial and vocal quality that might mediate these links. Potential explanatory constructs were selected on the basis of the following criteria: (a) They should be theoretically derived configural properties (i.e., not a single measure, such as nose length), (b) they should be definable in terms of objective stimulus information, (c) they should have documented perceiver agreement, and (d) they should have been demonstrated to exert a reliable and predictable impact on impressions. On the basis of these criteria, the variables of facial babyishness (cf. Berry \& McArthur, 1986), facial attractiveness (cf. Langlois, 1986), and vocal babyishness (cf. Montepare \& Zebrowitz-McArthur, 1987) were selected for study.' Faces were rated on 9-point bipolar scales, with endpoints of maturefaced-babyfaced and unattractive-attractive. Voices were rated on a scale with endpoints of mature voice-babyish voice.

Procedure: Perceptions of faces. A total of 71 judges made ratings of slides of the stimulus persons' faces. Approximately equal numbers of male and female raters were randomly assigned to rate one of two subsets of the men or to rate one of two subsets of the women (see Table 1), to view the stimulus persons in one of two orders, and to complete the dependent measures in one of three orders. The series of stimulus persons judged by a particular subject was presented a total of six times. During each of the first three presentations, subjects completed a subset of the nine trait scales. During the next two presentations, subjects rated the stimulus persons on facial attractiveness and facial babyishness. During the final presentation, subjects indicated whether they recognized any of the stimulus persons. ${ }^{2}$ Each slide was presented for approximately $15 \mathrm{~s}$. A pause separated each presentation of stimulus persons.

Procedure: Perceptions of voices. A total of 76 judges rated the stimulus persons' vaices. None of these judges had participated in the face-rating sessions described previously. Approximately equal numbers of men and women were randomly assigned to make ratings of one of two subsets of the male voices or one of two subsets of the female voices (see Table 1), to hear the subset of voices in one of two orders, and to complete the dependent measures in one of three orders. Judgments were made of the stimulus persons along the trait scales and along the dimension of vocal babyishness. Other details of the procedure were similar to that described above.

\section{Self-Perceptions of Stimulus Persons}

So that the correspondence of social perceptions and self-perceptions could be assessed, stimulus persons completed several self-report measures also selected to reflect the dimensions of power and warmth.

\footnotetext{
${ }^{1}$ It might be argued that facial attractiveness less clearly meets the first two criteria, as researchers have had problems identifying the origin of the attractiveness halo effect and the stimulus determinants that yield attractiveness (but see Cunningham, 1986; Cunningham, Barbee, \& Pike, 1990, and Langlois \& Roggman, 1990, for some important recent exceptions). Nevertheless, this variable was included because of the fact that its reliable impact on person perception has been extensively documented.

${ }^{2}$ Few judges recognized any of the stimulus persons. However, such responses were treated as missing data.
} 
These included 9-point bipolar trait scales with endpoints of submissive-dominant, strong-weak, kind-cruel, warm-cold, and dishonesthonest; the Rathus Assertiveness Scale (Rathus, 1973); and the Social Closeness, Social Potency, and Aggression subscales of the Multidimensional Personality Questionnaire (Tellegen, in press). The self-report data were obtained at a different time than the time of the photograph and voice recording. No mention of the relationship among these tasks was made to the subjects.

\section{Results}

\section{Data Base}

Social perceptions. Alphas were calculated to assess agreement among subjects' ratings of the stimulus persons' traits. ${ }^{3}$ These analyses were conducted separately for perceptions of male and female stimulus persons on the basis of facial information alone and on the basis of vocal information alone (see Table 1). The average alpha revealed for the trait dimensions

Table 1

Reliabilities of Perceptions of Stimulus Persons

\begin{tabular}{|c|c|c|c|c|}
\hline \multirow[b]{3}{*}{ Ratings } & \multicolumn{4}{|c|}{ Information provided } \\
\hline & \multicolumn{2}{|c|}{ Male } & \multicolumn{2}{|c|}{ Female } \\
\hline & Set $A$ & Set B & Set A & Set $B$ \\
\hline \multicolumn{5}{|c|}{ Face } \\
\hline \multicolumn{5}{|l|}{ Social perceptions } \\
\hline Strong & .85 & .80 & .76 & .87 \\
\hline Assertive & .75 & .85 & .77 & .73 \\
\hline Invulnerable & .72 & .84 & .80 & .84 \\
\hline Dominant & .70 & .82 & .77 & .88 \\
\hline Honest & .81 & .85 & .76 & .80 \\
\hline Warm & .88 & .83 & .91 & .88 \\
\hline Kind & .81 & .84 & .83 & .88 \\
\hline Naive & .73 & .80 & .74 & .78 \\
\hline \multicolumn{5}{|c|}{ Facial characteristics } \\
\hline Babyishness & .89 & .81 & .84 & .86 \\
\hline \multirow[t]{2}{*}{ Attractiveness } & .87 & .94 & .93 & .94 \\
\hline & \multicolumn{2}{|c|}{ Male } & \multicolumn{2}{|c|}{ Female } \\
\hline Ratings & Set A & Set B & Set $A$ & Set $\mathbf{B}$ \\
\hline \multicolumn{5}{|c|}{ Voice } \\
\hline \multicolumn{5}{|l|}{ Social perceptions } \\
\hline Strong & .89 & .86 & .97 & .99 \\
\hline Assertive & .91 & .86 & .92 & .97 \\
\hline Invulnerable & .85 & .76 & .94 & .98 \\
\hline Dominant & .88 & .74 & .97 & 99 \\
\hline Honest & .73 & .82 & .87 & .82 \\
\hline Warm & .79 & .91 & .83 & .90 \\
\hline Kind & .80 & .70 & .91 & .92 \\
\hline Naive & .83 & .83 & .94 & .99 \\
\hline Vocal babyishness & .93 & .89 & .97 & .96 \\
\hline
\end{tabular}

Note. For face, male Set $A$ faces $n=24$, male Set A judges $n=20$, male Set B faces $n=19$, male Set B judges $n=18$, female Set A faces $n=19$, female Set A judges $n=18$, female Set B faces $n=24$, female Set B judges $n=15$. For voice, male Set $A$ voices $n=24$, male Set $A$ judges $n=$ 20 , male Set B voices $n=19$, male Set B judges $n=17$, female Set A voices $n=19$, female Set A judges $n=19$, female Set B voices $n=24$, female Set $B$ judges $n=21$. was .84 and the average judge-total correlation was .47 . The mean rating a stimulus person received on each of these scales was calculated separately for each information condition. ${ }^{4}$

A varimax rotation factor analysis was performed on the trait ratings of the faces. On the basis of this analysis, the ratings were reduced to two dimensions. The first (factor loadings appear in parentheses) included ratings of the faces' strength (92), assertiveness (.86), invulnerability (.73), and dominance (94) and was called a facial power dimension. The second included perceived warmth (.96), honesty (.94), and kindness (.95) and was called a facial warmth dimension. Composite measures were created that reflected these two factors. Specifically, each composite consisted of the average of the ratings a stimulus face received on each incorporated scale.

A similar analysis of vocal impressions was conducted. This also yielded a power dimension, which incorporated ratings of strength (.96), assertiveness (.94), invulnerability (.92), and dominance (.97). A vocal power composite was created by combining these ratings. A vocal warmth dimension was also revealed. This included the rated warmth (.89), honesty (.65), and kindness $(.81)$ of voices. These were combined to create a vocal warmth composite. ${ }^{5}$

Facial and vocal characteristics. As can be seen in Table 1, alphas calculated among raters' judgments of the stimulus persons' facial and vocal characteristics were consistently high across conditions (mean $\alpha=.90$; mean judge-total correlation $=.58$ ). Thus, the average of the attractiveness and facial babyishness ratings each stimulus person received on the basis of only facial information was calculated for use in further analyses. The mean vocal babyishness rating received in the voiceonly condition was also computed for each stimulus person. Examination of the distribution of these ratings revealed sub-

\footnotetext{
${ }^{3}$ Analyses of rated straightforwardness-deceitfulness of the stimulus persons yielded very low reliabilities. Other studies of social perception using this particular rating scale have had similar results (Berry, 1990c; Montepare \& Zebrowitz-McArthur, 1987). Therefore, this scale was dropped and is not discussed further.

${ }^{4}$ The process of using the mean of the ratings provided by multiple judges to arrive at a normative judgment of an individual stimulus person, or face, or voice is referred to as the "consensual" method (cf. Alley, 1988). This is a standard procedure used in research on social perception (e.g., Berry, 1990b, 1990c, 1990d; Cunningham, 1986; Cunningham, Barbee, \& Pike, 1990; Langlois, Roggman, Casey, Ritter, Rieser-Danner, \& Jenkins, 1987; Montepare \& Zebrowitz-McArthur, 1987). In reliability analyses associated with this method, the stimulus person is treated as the unit of analysis and raters function as the "items" that are included in the measuring instrument. The average reliability obtained in the present research (collapsing across all scales) was .88, which is typical of such judgments (e.g., Berry, 1990c; Cunningham, 1986; Cunningham, Barbee, \& Pike, 1990; Montepare \& Zebrowitz-McArthur, 1987). These analyses further yielded, on average, a mean judge-total correlation of .54 , indicating that an individual judge's ratings have an average correlation of .54 with the normative judgment. The average interrater (item) correlation was . 34 .

${ }^{5}$ The dimension of naiveté bore significant but moderate correlations to both the power and warmth dimensions for impressions of both faces and voices. Given that naïveté was not exclusively related to either dimension, ratings along this scale were not incorporated into either composite.
} 
stantial variation in each for both male and female stimulus persons. Specifically, facial babyishness ranged from 1.65 to 7.35 with a mean of 5.00 for men and from 2.06 to 7.57 with a mean of 4.80 for women. Attractiveness ratings ranged from 2.06 to 7.11 with a mean of 4.18 for men, and from 1.39 to 7.11 with a mean of 4.20 for women. Vocal babyishness ranged from 2.53 to 7.76 with a mean of 4.35 for men and from 2.42 to 7.84 with a mean of 5.10 for women.

Consistent with previous research (Berry, in press), correlational analyses revealed that facial babyishness and facial attractiveness were not related for either men or women, $r s(41)=.02$ and -.07 , respectively, $n s$. Facial babyishness and vocal babyishness were positively correlated for men, $r(41)=.35, p<$ .05 , and marginally correlated for women, $r(41)=.28, p<.07$. A positive correlation was also revealed between men's facial attractiveness and vocal babyishness, $r(41)=.35, p<.05$. This relation was not revealed for female stimulus persons, $r(41)=$ $.14, n s$.

Self-ratings. A varimax rotation factor analysis was performed on self-ratings along the trait scales. This revealed that these could be more concisely described in terms of a power and a warmth dimension. Self-ratings of (factor loadings appear in parentheses) assertiveness (89) and dominance (89) were averaged to create a self-judged power composite; and self-perceived honesty (.74), kindness (.80), and warmth (.84) were averaged to create a self-judged warmth composite.

\section{Social Perception: Impact of Face and Voice}

Correlational analyses were conducted to examine the relations of facial babyishness and attractiveness to face-only judgments. The results of these analyses were consistent with previous research (e.g., Berry \& McArthur, 1986; Cunningham, 1986). In particular, facial babyishness was negatively associated with ratings of facial power, partial $r(83)=-.64, p \leq .001$ (sex was controlled in partial correlations). Babyfacedness was also positively related to the perceived warmth of stimulus persons, partial $r(83)=.49, p \leq .001$. Attractiveness was positively related to impressions of power, partial $r(83)=.42, p \leq .001$, and to the judged warmth of stimulus persons, partial $r(83)=$ $.37, p \leq .001$. Also, as was found in previous research, vocal babyishness was found to predict voice-based impressions (Montepare \& Zebrowitz-McArthur, 1987). In particular, vocal babyishness was negatively related to judged power, partial $r(83)=-.60, p \leq .001$, and positively related to stimulus persons' perceived warmth, partial $r(83)=.31, p<.001$.

\section{Relations of Face- and Voice-Based Impressions to Men's Self-Views}

Power. Did impressions of the male stimulus persons' power on the basis of facial or vocal information alone predict their self-views? To address this, four separate multiple regression analyses were performed in which the judged power of men on the basis of facial information (facial power) and on vocal information (vocal power) were simultaneously entered as predictors of their self-ratings of assertiveness, social potency, aggression, and their self-judged power. As can be seen in Table 2 , facial power emerged as a significant predictor of all four of these self-ratings. Specifically, men whose faces were judged to look powerful tended to be high scorers on the scales of assertiveness, social potency, and aggression, and to describe themselves as being powerful. Vocal power only emerged as a significant predictor of scores on the Assertiveness scale.

Could the characteristics of facial attractiveness, facial babyishness, or vocal babyishness explain these links? To address this question, four multiple regression analyses were conducted in which these facial, vocal or facial and vocal qualities were considered as predictors of the four self-ratings of power. Because face-based impressions predicted all four self-ratings, facial attractiveness and facial babyishness were included as predictors in each of the equations. Vocal babyishness was included only as a predictor of assertiveness, as vocal impressions had been related only to this measure. In these analyses, the relevant facial, vocal, or facial and vocal characteristics were simultaneously entered as predictors of a given self-rating. As can be seen in Table 3, facial attractiveness was a significant predictor of men's assertiveness and social potency scores, as well as their self-ratings on trait scales related to power. Consistent with data from a previous study (Berry \& Brownlow, 1989), facial babyishness accounted for a significant proportion of the variance in men's aggression scores. No other significant predictors of these dimensions were revealed.

Analyses were performed to assess whether facial attractiveness could completely account for the relation of facial power to assertiveness, social potency, and self-rated power (see Table 4). Specifically, separate regression equations were computed for each of these three measures. In each, facial attractiveness was entered on the first step and facial power was entered on the second step. The intent of this approach was to assess whether facial power could account for significant proportions of the variance in the dependent measures beyond that explained by attractiveness. As can be seen in Table 4, facial power did add significantly to the explained variance in the equations predicting assertiveness and self-judged power traits. Facial power did not significantly add to the variance explained in social potency scores.

A similar analysis was performed on men's aggression scores. Because facial babyishness had been revealed to bear a relation to these scores, it was entered on Step 1 of the regression, and facial power was entered on Step 2. The addition of facial power to the equation did not yield a significant increase in explained variance (see Table 4). Therefore, facial babyishness may account for the links revealed between facial power and aggression.

Warmth. Regression analyses were conducted in which ratings of the men's warmth on the basis of face only (facial warmth) and ratings of the warmth of their voices (vocal warmth) were simultaneously entered as predictors of social closeness scores and of self-ratings along trait scales related to warmth (see Table 2). These analyses revealed that men whose faces were rated as warm were also high scorers on the Social Closeness scale and that they gave themselves high ratings on trait scales related to warmth. Vocal warmth did not bear a significant relation to either of these self-ratings.

Could facial babyishness or attractiveness explain the links revealed between face-based impressions of warmth and selfviews of warmth? To address this question, regression analyses 
Table 2

Results of Multiple Regression Analyses Predicting Men's Self-Ratings From Face- and Voice-Based Impressions

\begin{tabular}{|c|c|c|c|c|c|c|}
\hline $\begin{array}{l}\text { Dependent } \\
\text { variable }\end{array}$ & $\begin{array}{l}\text { Predictor } \\
\text { variable }\end{array}$ & Step & $r$ & $\begin{array}{c}\text { Partial } \\
r\end{array}$ & $\begin{array}{c}\text { Standardized } \\
\beta \\
\end{array}$ & $t$ \\
\hline \multicolumn{7}{|l|}{ Power } \\
\hline \multirow[t]{2}{*}{ Rathus assertiveness } & Facial power & 1 & .51 & .53 & .51 & $3.94^{* * *}$ \\
\hline & Vocal power & 1 & .26 & .31 & .27 & $2.03^{*}$ \\
\hline \multirow[t]{2}{*}{ MPQ social potency } & Facial power & I & .36 & .36 & .36 & $2.45^{*}$ \\
\hline & Vocal power & 1 & .15 & .15 & .15 & 1.03 \\
\hline \multirow{2}{*}{ MPQ aggression } & Facial power & 1 & .33 & .33 & .32 & $2.14^{*}$ \\
\hline & Vocal power & 1 & .05 & .05 & .05 & 0.30 \\
\hline \multirow{2}{*}{ Self-judged power } & Facial power & 1 & .47 & .47 & .47 & $3.45^{* *}$ \\
\hline & Vocal power & 1 & .14 & .14 & .14 & 1.05 \\
\hline \multicolumn{7}{|l|}{ Warmth } \\
\hline \multirow[t]{2}{*}{ Social closeness } & Facial warmth & 1 & .33 & .32 & .32 & $2.00^{*}$ \\
\hline & Vocal warmth & 1 & .19 & .14 & .13 & 0.90 \\
\hline \multirow[t]{2}{*}{ Self-judged warmth ${ }^{b}$} & Facial warmth & 1 & .34 & .37 & .73 & $2.52^{*}$ \\
\hline & Vocal warmth & 1 & -.08 & -.16 & -.15 & -1.01 \\
\hline
\end{tabular}

Note. $N=43 ; d f$ s vary slightly because of missing data. $\mathrm{MPQ}=$ Multidimensional Personality Questionnaire (Tellegen, in press).

Includes self-ratings along trait scales with endpoints of not assertive-assertive and submissive-dominant.

${ }^{b}$ Includes self-ratings along trait scales with endpoints of dishonest-honest, cruel-kind, and cold-warm.

${ }^{*} p<.05 .^{* *} p<.01{ }^{* * *} p<.001$.

were conducted in which these two variables were simultaneously entered as predictors of social closeness scores and selfratings on the warmth trait scales (see Table 3). No significant relations among these variables were revealed.

Summary. Impressions that were based on facial information did predict men's self-views of power and warmth. In particular, men whose faces looked powerful were higher scorers on the dimensions of assertiveness, social potency, aggression, and self-judged power than were men with a facial appearance that was rated as less powerful. It was further revealed that variations in facial attractiveness may explain the relation between facial power and social potency and that variations in facial babyishness may explain the link between facial power and aggression. However, although attractiveness was also related to

Table 3

Results of Multiple Regression Analyses Predicting Men's Self-Ratings

From Facial and Vocal Characteristics

\begin{tabular}{|c|c|c|c|c|c|c|}
\hline $\begin{array}{c}\text { Dependent } \\
\text { variable }\end{array}$ & $\begin{array}{c}\text { Predictor } \\
\text { variable }\end{array}$ & Step & $r$ & $\begin{array}{c}\text { Partial } \\
r\end{array}$ & $\begin{array}{c}\text { Standardized } \\
\beta \\
\end{array}$ & $t$ \\
\hline \multicolumn{7}{|l|}{ Power } \\
\hline \multirow[t]{3}{*}{ Rathus assertiveness } & Facial attractiveness & 1 & .43 & .49 & .51 & $3.49^{* *}$ \\
\hline & Facial babyishness & 1 & -.27 & -.24 & -.22 & -1.54 \\
\hline & Vocal babyishness & 1 & -.09 & -.20 & -.20 & -1.26 \\
\hline \multirow{2}{*}{ MPQ social potency } & Facial attractiveness & 1 & .40 & .40 & .40 & $2.78^{* *}$ \\
\hline & Facial babyishness & 1 & .02 & .01 & .01 & 0.07 \\
\hline \multirow[t]{2}{*}{ MPQ aggression } & Facial attractiveness & 1 & .20 & .21 & .20 & 1.35 \\
\hline & Facial babyishness & 1 & -.33 & -.34 & -.33 & $-2.22^{*}$ \\
\hline \multirow[t]{2}{*}{ Self-judged power" } & Facial attractiveness & 1 & .38 & .39 & .38 & $2.66^{* *}$ \\
\hline & Facial babyishness & 1 & -.13 & -.15 & -.14 & -0.98 \\
\hline \multicolumn{7}{|l|}{ Warmth } \\
\hline \multirow[t]{2}{*}{ Social closeness } & Facial attractiveness & 1 & .27 & .28 & .27 & 1.81 \\
\hline & Facial babyishness & 1 & -.07 & -.08 & -.08 & -0.52 \\
\hline \multirow[t]{2}{*}{ Self-judged warmth } & Facial attractiveness & 1 & .22 & .21 & .22 & 1.41 \\
\hline & Facial babyishness & 1 & .01 & -.01 & -.01 & -0.02 \\
\hline
\end{tabular}

Note. $n=43 ; d f \mathrm{~s}$ vary slightly because of missing data. $\mathrm{MPQ}=$ Multidimensional Personality Questionnaire (Tellegen, in press).

ancludes self-ratings along trait scales with endpoints of not assertive-assertive and submissive-dominant.

${ }^{-}$Includes self-ratings along trait scales with endpoints of dishonest-honest, cruel-kind, and cold-warm.

${ }^{*} p<.05 .{ }^{* *} p<.01$. 
Table 4

Results of Multiple Regression Analyses Predicting Men's Self-Ratings

From Facial Characteristics and Facial Power

\begin{tabular}{llccccc}
\hline $\begin{array}{c}\text { Dependent } \\
\text { variable }\end{array}$ & \multicolumn{1}{c}{$\begin{array}{c}\text { Predictor } \\
\text { variable }\end{array}$} & Step & $R_{\mathrm{ch}}{ }^{2}$ & $R_{\mathrm{eq}}{ }^{2}$ & $F_{\mathrm{ch}}$ & $F_{\mathrm{cq}}$ \\
\hline Rathus assertiveness & Facial attractiveness & 1 & .19 & .19 & $9.09^{* *}$ & $9.09^{* *}$ \\
& Facial power & 2 & .12 & .31 & $6.89^{*}$ & $8.60^{* * *}$ \\
MPQ social potency & Facial attractiveness & 1 & .17 & .17 & $7.95^{* *}$ & $7.95^{* *}$ \\
& Facial power & 2 & .03 & .20 & 1.67 & $4.88^{*}$ \\
MPQ aggression & Facial babyishness & 1 & .11 & .11 & $4.82^{*}$ & $4.82^{*}$ \\
& Facial power & 2 & .02 & .13 & 0.89 & 2.85 \\
Self-judged power & Facial attractiveness & 1 & .15 & .15 & $6.98^{*}$ & $6.98^{*}$ \\
& Facial power & 2 & .11 & .26 & $5.84^{*}$ & $6.82^{*}$ \\
\hline
\end{tabular}

Note. $n=43 ; d f s$ vary slightly because of missing data. $\mathrm{MPQ}=$ Multidimensional Personality Questionnaire (Tellegen, in press); $R_{\mathrm{ch}}{ }^{2}=$ change in $R^{2} ; R_{\mathrm{eq}}{ }^{2}=R^{2}$ for the overall equation; $F_{\mathrm{ch}}=$ change in $\mathrm{F} ; F_{\mathrm{eq}}=F$ for the overall equation.

ancludes self-ratings along trait scales with endpoints of not assertive-assertive and submissive-dominant.

$* p<.05 .^{* *} p<.01 .^{* * *} p<.001$.

assertiveness and self-rated power, this facial quality could not account for the links between facial power and those self-ratings. The data also revealed a relation between face-based impressions and self-views of warmth. In particular, men with faces that look warm had higher social closeness scores and higher self-ratings of warmth than did men with faces that were judged to look less warm. These relations could not be explained by variations in either facial attractiveness or babyishness. Vocal impressions were related only to self-ratings of assertiveness. Specifically, men's assertiveness scores were positively related to the perceived powerfulness of their voices. Vocal babyishness could not account for this relation.

\section{Relations of Face- and Vice-Based Impressions to Women's Self-Views}

Power. Four separate multiple regression analyses were conducted in which facial power and vocal power were simultaneously entered as predictors of women's assertiveness, social potency, and aggression scores and self-rated power (see Table 5 ). These analyses revealed that women with powerful-looking faces obtained higher social potency scores and gave themselves higher ratings on power-related traits than did women with less powerful-looking faces. Vocal power was also related to these self-views. Specifically, women with voices that were thought to sound powerful tended to be high scorers on the Aggression scale and to describe themselves as powerful. Neither facial nor vocal power were related to assertiveness scores.

Regression analyses were conducted to assess whether attractiveness, facial babyishness, or vocal babyishness could explain any of the links described above. In these analyses, subsets of these characteristics as predictors of the dependent variables. As facial information had predicted women's social potency and self-judged power scores, facial babyishness and attractiveness were both considered to be predictors of those dimensions in the analyses. Vocal babyishness was also included as a predictor of the measures of aggression and self-judged power (see Table 6).
Only one significant relation between these facial and vocal qualities and self-ratings was revealed: Women's vocal babyishness was negatively related to their aggression scores. An additional regression equation was computed to assess whether vocal babyishness accounted for the observed relation between vocal power and aggression. Specifically, vocal babyishness was entered as a predictor of aggression on Step 1 and vocal power was entered on Step 2. The entry of vocal power into the equation did not produce a significant increase in $R^{2}, F<1, n s$, indicating that variations in vocal babyishness may yield the links between vocal power and aggression.

Warmth. Regression analyses were conducted to assess whether impressions of warmth that were based on facial or vocal information predicted self-ratings of warmth. Specifically, facial warmth and vocal warmth were simultaneously entered as predictors of social closeness and self-ratings on warmth-related traits. As can be seen in Table 5, facial warmth did not predict either of these measures. However, the perceived warmth of women's voices was positively related to their social closeness scores. To assess whether vocal babyishness could account for this relation, an analysis was conducted in which vocal babyishness was entered as a predictor of social closeness (see Table 6). Women's vocal babyishness was not related to their scores on this measure.

Summary. Judgments of women's facial power predicted their social potency and self-judged power scores. Neither facial attractiveness nor facial babyishness could explain these links. Face-based ratings were not related to any other self-ratings. Vocal power was revealed to predict aggression and self-rated power scores, and variations in vocal babyishness could account for the link between aggression and vocal power. Voicebased impressions of women also predicted women's social closeness scores. This relation could not be explained by variations in vocal babyishness.

\section{Discussion}

The primary goal of this study was to examine the relations between impressions that were based on face or voice and self- 
Table 5

Results of Multiple Regression Analyses Predicting Womens Self-Ratings

From Face- and Voice-Based Impressions

\begin{tabular}{|c|c|c|c|c|c|c|}
\hline $\begin{array}{l}\text { Dependent } \\
\text { variable }\end{array}$ & $\begin{array}{c}\text { Predictor } \\
\text { variable }\end{array}$ & Step & $r$ & $\begin{array}{c}\text { Partial } \\
r \\
\end{array}$ & $\begin{array}{c}\text { Standardized } \\
\beta \\
\end{array}$ & $t$ \\
\hline \multicolumn{7}{|l|}{ Power } \\
\hline \multirow[t]{2}{*}{ Rathus assertiveness } & Facial power & 1 & .26 & .26 & .25 & 1.69 \\
\hline & Vocal power & 1 & .13 & .13 & .12 & 0.86 \\
\hline \multirow[t]{2}{*}{ MPQ social potency } & Facial power & 1 & .33 & .32 & .32 & $2.10^{*}$ \\
\hline & Vocal power & 1 & .15 & .13 & .13 & 0.85 \\
\hline \multirow{2}{*}{ MPQ aggression } & Facial power & 1 & .13 & .11 & .11 & 0.71 \\
\hline & Vocal power & 1 & .32 & .32 & .31 & $2.01^{*}$ \\
\hline \multirow[t]{2}{*}{ Self-judged power" } & Facial power & 1 & .33 & .35 & .31 & $2.33^{*}$ \\
\hline & Vocal power & 1 & .42 & .43 & .41 & $3.03^{*}$ \\
\hline \multicolumn{7}{|l|}{ Warmth } \\
\hline \multirow[t]{2}{*}{ Social closeness } & Facial warmth & 1 & -.06 & -.15 & -.14 & -0.95 \\
\hline & Vocal warmth & 1 & .32 & .35 & .36 & $2.23^{*}$ \\
\hline \multirow[t]{2}{*}{ Self-judged warmth ${ }^{b}$} & Facial warmth & 1 & .14 & .10 & .11 & 0.66 \\
\hline & Vocal warmth & 1 & .14 & .10 & .11 & 0.66 \\
\hline
\end{tabular}

Note. $n=43 ; d f$ s vary slightly because of missing data. $\mathrm{MPQ}=$ Multidimensional Personality Questionnaire (Tellegen, in press).

Includes self-ratings along trait scales with endpoints of not assertive-assertive and submissive-dominant.

'Includes self-ratings along trait scales with endpoints of dishonest-honest, cruel-kind, and cold-warm.

$* p<.05$.

ratings: The data reveal that impressions that were based only on a facial photograph or on a neutral-voice recording can predict self-views. These results suggest that impressions based on relatively enduring aspects of facial and vocal quality may have some validity. Moreover, these links may account for the agreement between self- and stranger judgments that has been revealed by studies of interpersonal perception (e.g., Berry, 1990b; Kenny et al., 1990).

Impressions based on facial appearance predicted all self-ratings provided by male stimulus persons, as well as women's self-judged power and social potency. Voice-based impressions predicted men's assertiveness scores and women's social closeness scores, aggression scores, and self-ratings of power. It was not expected that a pattern of relations between facial appearance and self-ratings would be more consistent for male than for female stimulus persons, as appearance has traditionally weighed more heavily in the evaluation of women than of men. Given this, it would seem prudent to await a replication of this sex difference with other samples before interpreting this result.

Several specific facial qualities were related to self-views, and the directions of these relations were all consistent with research on first impressions. Specifically, facial attractiveness was positively related to men's assertiveness and social potency scores and self-ratings of power. To the extent that dominance, assertiveness, and strength are stereotypically considered to be desirable masculine traits, these data are in accord with the

Table 6

Results of Multiple Regression Analyses Predicting Womens Self-Ratings

From Facial and Vocal Characteristics

\begin{tabular}{|c|c|c|c|c|c|c|}
\hline $\begin{array}{l}\text { Dependent } \\
\text { variable }\end{array}$ & $\begin{array}{l}\text { Predictor } \\
\text { variable }\end{array}$ & Step & $r$ & $\begin{array}{c}\text { Partial } \\
r\end{array}$ & $\begin{array}{c}\text { Standardized } \\
\beta\end{array}$ & $t$ \\
\hline \multicolumn{7}{|l|}{ Power } \\
\hline \multirow[t]{2}{*}{ MPQ social potency } & Facial attractiveness & 1 & -.07 & -.09 & -.09 & -0.52 \\
\hline & Facial babyishness & 1 & -.08 & -.09 & -.09 & -0.53 \\
\hline MPQ aggression & Vocal babyishness & 1 & -.33 & -.33 & -.33 & $-2.16^{*}$ \\
\hline \multirow[t]{3}{*}{ Self-judged power" } & Facial attractiveness & 1 & -.01 & .00 & .00 & 0.02 \\
\hline & Facial babyishness & 1 & -.14 & -.09 & -.09 & -0.56 \\
\hline & Vocal babyishness & 1 & -.20 & -.17 & -.18 & -1.08 \\
\hline \multicolumn{7}{|l|}{ Warmth } \\
\hline Social closeness & Vocal babyishness & 1 & .17 & .17 & .17 & 1.09 \\
\hline
\end{tabular}

Note. $n=43 ; d f$ s vary slightly because of missing data. $\mathrm{MPQ}=$ Multidimensional Personality Questionnaire (Tellegen, in press).

"Includes self-ratings along trait scales with endpoints of not assertive-assertive and submissive-dominant.

$* p<.05$. 
attractiveness halo effect (e.g., Berry, in press; Morse, Reis, Gruzen, \& Wolff, 1974). Consistent with this observation, the one self-rating related to power that was not predicted by male attractiveness was aggression. This is also the power dimension that is most likely to be perceived as negative. Also consistent with previous research on first impressions, facial babyishness was negatively related to men's aggression scores, and vocal babyishness was negatively correlated with women's aggression scores.

Although links between self-ratings and specific qualities such as attractiveness and babyishness were documented, it is noteworthy that these variables did not entirely explain the face or voice effects revealed. ${ }^{6}$ In particular, previous work on the validity of impressions of faces has typically been focused on the relations between attractiveness ratings and measures of personality. That attractiveness cannot fully explain the parallels revealed between self-view and face-based impressions suggests that previous research may have underestimated the links between impressions based on overall facial appearance and individual differences by limiting their study to this one construct. Facial appearance is an extremely complex variable, of which attractiveness is only one dimension. It is clear that analyses of the additional stimulus determinants of facial appearance that may influence self- and stranger impressions is needed.

Given that matches between self-reports and perceptions that are based on relatively enduring aspects of overall facial appearance and vocal quality do exist, how might they develop? One appealing explanation of the data involves a behavioral confirmation model. This proposes that people whose faces and voices yield robust expectations about their dispositional qualities may be treated as though they indeed possess those qualities. During the course of a given interaction, a perceiver may act in a way that actually elicits the expected responses from a target person. Such self-fulfilling prophecy effects have been observed within initial interactions in response to appearance-based expectations (e.g., Snyder, Tanke, \& Berscheid, 1977). Several researchers have further proposed that repeated participation in such encounters may result in target persons internalizing the originally erroneous expectations communicated to them (e.g., Adams, 1977; Langlois, 1986; McArthur, 1982). Thus, consistent expectations that are repeatedly elicited by one's facial and vocal characteristics may mold one's selfview and, presumably, one's likely behaviors.

A second explanation that has received less attention is that certain dispositional attributes may be directly expressed by particular nonverbal qualities. ${ }^{7}$ Perceivers thus may attribute personality qualities to particular nonverbal cues because they have become sensitive to true covariances that exist among those variables. Such a model has been proposed by Scherer (1972) to explain the links observed between certain vocal parameters and personality traits. It seems reasonable to assume that links between person qualities and vocal characteristics may exist. For example, Montepare and Vega (1988) reported that when women talk with intimate male friends, their voices are judged to sound more approachable and sincere than when they talk with casual male friends. As we indeed feel more approachable and sincere when interacting with intimate friends than with other people, this suggests that people have the capacity to subtly modulate the sounds of their voices in a fashion that provides accurate information about them.

It seems to be more difficult to alter one's facial configuration than one's voice. Given this, how might disposition be expressed by static facial appearance? Malatesta, Fiore, and Messina (1987) have described one way in which one's face may come to mirror one's disposition. Subjects in this study were asked to rate neutral facial photographs of older adult women for emotion expression. In addition, the women who appeared in the photographs completed Izard's (1972) Differential Emotions Scale (DES), which assesses the frequency with which individuals tend to experience particular emotions. Malatesta and her associates found that neutral facial poses were often mistakenly identified as a particular facial expression. Moreover, individuals' scores on the DES predicted these errors. For example, people who reported experiencing much anger exhibited neutral expressions that were often perceived to be hostile. Malatesta and her associates suggested that facial qualities such as wrinkle patterns may be influenced by the frequency with which particular emotions are facially expressed. The stimulus persons in the present research were young adults, making this particular determinant of personality-appearance relationships unlikely. However, recent research has indicated that people can subtly modulate their facial pose in a manner that exerts an impact on trait impressions, even while maintaining a facial expression that is judged to be neutral (Berry \& Finch, 1991). This suggests that individuals may either consciously or unconsciously directly express their dispositional properties through subtle facial manipulations. Additional research on this topic seems warranted.

Whether the links between self-view and nonverbal qualities revealed in this study are the result of self-fulfilling prophecy, direct expression, or a combination of the two is unknown at this point. Developmental research could provide a key to addressing this question. In particular, an age-related convergence between self- or peer ratings and those that are based on nonverbal cues could provide evidence for the role of behavioral confirmation in producing the effects observed here in young adults.

In the present research, self-reports and personality tests

\footnotetext{
${ }^{6}$ After this research was conducted, work describing a dimension of vocal attractiveness that influences impressions in a similar manner as facial attractiveness appeared (Zuckerman \& Driver, 1989). Subsequent research has revealed no consistent relation between vocal attractiveness and self-view (Berry, 1990c). Therefore, it seems unlikely that variations in vocal attractiveness would explain the effects reported here.

${ }^{7}$ The concept of direct expression should not be confused with the views espoused by the physiognomists, who proposed mystical links between personality and facial qualities, in lieu of either data or an elucidation of reasonable causal mechanisms to explain the links they proposed. My use of the term is derived from the ecological and ethological views that "form follows function," and that internal (dispositional) properties may constrain the appearance of animate as well as inanimate entities by way of mechanisms such as that proposed by Malatesta, Fiore, \& Messina (1987; see also Berry, 1990a; Berry \& McArthur, 1986; McArthur \& Baron, 1983; Shapiro \& Eppler, 1989).
} 
were used as the baseline against which the validity of social perception was tested. Although such measures have been used in many studies for a similar purpose (e.g., Albright, Kenny, \& Malloy, 1988; Berry, 1990b; Watson, 1989; see also Funder, 1987; Shrauger \& Osberg, 1981), it must be acknowledged that there is controversy regarding what measures constitute an appropriate criterion for accuracy (cf. Funder \& Colvin, 1988; Schneider, Hastorf, \& Ellsworth, 1979). However, in addition to the match revealed here between self-perceptions and judgments that were based on facial and vocal information, research has documented parallels between photograph-based ratings and descriptions provided by acquaintances (Berry, 1990b). There is also recent evidence that face-based impressions do predict behavioral responses. In particular, Bond, Berry, and Omar (1991) found that people whose faces were thought to look dishonest were more likely to volunteer for an experiment that would involve lying to their peers than were people with faces judged to look honest. To the extent that convergence among the results revealed by studies that use multiple criteria is found, the case for accuracy becomes stronger. More research using behavioral observation as a baseline measure seems useful. Regardless of whether a match between impressions that are based on nonverbal characteristics and behavior-based judgments exists, however, the match between such impressions and self-view is an interesting phenomenon. Moreover, the findings indicate that judgments based on facial and vocal information represent psychologically meaningful constructs that have important ramifications for the perceived, as well as for the perceiver.

\section{References}

Adams, G. R. (1977). Physical attractiveness research: Toward a developmental social psychology of beauty. Human Development, 20 , 217-239.

Albright, L., Kenny, D. A., \& Malloy, T. E. (1988). Consensus in personality judgments at zero acquaintance. Journal of Personality and Social Psychology, 55, 387-395.

Alley, T. R. (1988). Physiognomy and social perception. In T. R. Alley (Ed.), Social and applied aspects of perceiving faces (pp. 167-186). Hillsdale, NJ: Erlbaum.

Berry, D. S. (in press). Attractive faces are not all created equal: Joint effects of facial babyishness and attractiveness on social perception. Personality and Social Psychology Bulletin.

Berry, D. S. (1990a). The perceiver as naive scientist or the scientist as naive perceiver? An ecological view of social knowledge acquisition. Contemporary Social Psychology, 14, 145-153.

Berry, D. S. (1990b). Taking people at face value: Evidence for the kernel of truth hypothesis. Social Cognition, 8, 343-361.

Berry, D. S. (1990c). Vocal attractiveness: Effects on stranger, self and friend impressions. Journal of Nonverbal Behavior, 14, 141-153.

Berry, D. S. (1990d). What can a moving face tell us? Journal of Personality and Social Psychology, 58, 1004-1014.

Berry, D. S., \& Brownlow, S. (1989). Were the physiognomists right? Personality correlates of facial babyishness. Personality and Social Psychology Bulletin, 15, 266-279.

Berry, D. S., \& Finch, J. L. (1991). The face of power: Effects of variations in facial pose on social perception. Manuscript in preparation, Southern Methodist University, Dallas, TX.

Berry, D. S., \& McArthur, L. Z. (1986). Perceiving character in faces:
The impact of age-reiated craniofacial changes on social perception. Psychological Bulletin, 100, 3-18.

Bond, C. F., Jr., Berry, D. S., \& Omar, A. (1991). The 'kernel of truth' in judgments of deception. Manuscript in preparation, Texas Christian University, Fort Worth, and Southern Methodist University, Dallas. Cunningham, M. R. (1986). Measuring the physical in physical attractiveness: Quasi-experiments on the sociobiology of female facial beauty. Journal of Personality and Social Psychology, 50, 925-935.

Cunningham, M. R., Barbee, A. P., \& Pike, C. L. (1990). What do women want? Facial metric assessment of multiple motives in the perception of male facial physical attractiveness. Journal of Personality and Social Psychology, 58, 61-72.

Funder, D. C. (1987). Errors and mistakes: Evaluating the accuracy of social judgment. Psychological Bulletin, 101, 75-90.

Funder, D. C., \& Colvin, C. R. (1988). Friends and strangers: Acquaintanceship, agreement, and the accuracy of personality judgment. Journal of Personality and Social Psychology, 55, 149-158.

Izard, C. E. (1972). Patterns of emotion: $A$ new analysis of anxiety and depression. San Diego, CA: Academic Press.

Kenny, D. A., Horner, C., Kashy, D. A., \& Chu, L. (1990). Consensus at zero-acquaintance: Replication, mediation and stability. Unpublished manuscript, University of Connecticut, Storrs.

Langlois, J. H. (1986). From the eye of the beholder to behavioral reality: Development of social behaviors and social relations as a function of physical attractiveness. In C. P. Herman, M. P. Zanna, \& E. T. Higgins (Eds), Physical appearance, stigma, and social behavior (pp. 23-52). Hillsdale, NJ: Erlbaum.

Langlois, J. H., \& Roggman, L. A. (1990). Attractive faces are only average. Psychological Science, 1, 115-121.

Langlois, J. H., Roggman, L. A., Casey, R. J., Ritter, J. M., Rieser-Danner, L. A., \& Jenkins, V. Y. (1987). Infant preferences for attractive faces: Rudiments of a stereotype? Developmental Psychology, 23. 363-369.

Lippa, R. (1983). Expressive behavior. In L. Wheeler \& P. Shaver (Eds.), Review of Personality and Social Psychology, (pp. 181-205). Beverly Hills, CA: Sage.

Malatesta, C. Z., Fiore, M. J., \& Messina, J. J. (1987). Affect, personality and facial expressive characteristics of older people. Psychology and Aging, 2, 64-69.

McArthur, L. Z. (1982). Judging a book by its cover: A cognitive analysis of the relationship between physical appearance and stereotyping. In A. Hastorf \& A. Isen (Eds.), Cognitive Social Psychology (pp. 149-211). New York: Elsevier/North-Holland.

McArthur, L. Z., \& Baron, R. M. (1983). Toward an ecological theory of social perception. Psychological Review, 90, 215-238.

Montepare, J. M., \& Vega, C. (1988). Women's vocal reactions to intimate and casual friends. Personality and Social Psychology Bulletin, 14, 103-113.

Montepare, J. M., \& Zebrowitz-McArthur, L. (1987). Perceptions of adults with childlike voices in two cultures. Journal of Experimental Sacial Psychology, 23, 331-349.

Morse, S., Reis, H., Gruzen, J., \& Wolff, E. (1974). The "eye of the beholder": Determinants of physical attractiveness judgments in the U.S. and South Africa. Journal of Personality, 42, 528-542.

Rathus, S. A. (1973). A 30 -item schedule for assessing assertive behavior. Behavior Therapy, 4, 398-406.

Riggio, R. E., Lippa, R., \& Salinas, C. (1990). The display of personality in expressive movement. Journal of Research in Personality, 24, 1631.

Scherer, K. R. (1972). Judging personality from voice: A cross-cultural approach to an old issue in interpersonal perception. Journal of Personality, 40, 191-210. 
Scherer, K. R. (1978). Personality inference from voice quality: The loud voice of extroversion. European Journal of Social Psychology, 8 , 467-487.

Schneider, D. J., Hastorf, A. H., \& Ellsworth, P. C. (1979). Person perception. Reading, MA: Addison-Wesley.

Shapiro, B. A., \& Eppler, M. (1989). An ecological analysis of facial information. In A. W. Young \& H. D. Ellis (Eds), Handbook of research on face processing. Amsterdam: North-Holland.

Shrauger, J. S., \& Osberg, T. M. (1981). The relative accuracy of self-predictions and judgments by others in psychological assessment. $P_{S y}$ chological Bulletin, 90, 322-351.

Siegman, A. W. (1987). The telltale voice: Nonverbal messages of verbal communication. In A. W. Siegman \& S. Feldstein (Eds.), Nonverbal behavior and communication (pp. 351-431). Hillsdale, NJ: Erlbaum.
Snyder, M., Tanke, E. D., \& Berscheid, E. (1977). Social perception and social behavior: On the self-fulfilling nature of social stereotypes. Journal of Personality and Social Psychology, 35, 656-666.

Tellegen, A. (in press). The Multidimensional Personality Questionnaire. Minneapolis, MN: National Computer Services.

Watson, D. (1989). Strangers' ratings of the five robust personality factors: Evidence of a surprising accuracy. Journal of Personality and Social Psychology, 57, 120-128.

Zuckerman, M., \& Driver, R. (1989). What sounds beautiful is good: The vocal attractiveness stereotype. Journal of Nonverbal Behavior, $13,67-82$.

Received June 13, 1989

Revision received September 24, 1990 Accepted January 18, 1991 